Article

\title{
The Importance of Packaging Functions for Food Waste of Different Products in Households
}

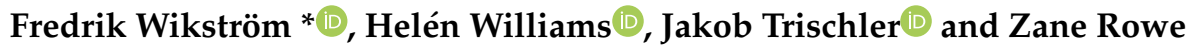 \\ Environmental and Energy Systems, CTF Service Research Center, Karlstad University, S-651 88 Karlstad, \\ Sweden; helen.williams@kau.se (H.W.); jakob.trischler@kau.se (J.T.); zane.rowe@kau.se (Z.R.) \\ * Correspondence: fredrik.wikstrom@kau.se
}

Received: 23 April 2019; Accepted: 3 May 2019; Published: 8 May 2019

\begin{abstract}
The United Nations sustainability goal SDG 12.3 is to reduce the amount of food that is wasted by half, due to environmental and social reasons. This paper aims to analyse the most important packaging functions that affect food waste in households for different products, as the reason for wastage can be expected to differ between different products. The reasons for food wastage of different categories and products have been compiled through literature studies, and possible improvements of packaging functions to reduce food waste have been identified. In addition, an expert workshop judged the most important packaging functions to reduce food waste for a number of products. They also discussed the obstacles and possibilities to realise the packaging improvements. This study confirms that how packaging functions influence food waste on the product level is a highly unexplored question. Most likely, there is high potential to reduce food waste through better adaptions of packaging functions to user needs and habits. Both the literature study and the expert workshop show that less food per pack and better information regarding food safety and storage have high potential to reduce food waste, but also that product specific considerations are necessary.
\end{abstract}

Keywords: food waste; packaging functions; packaging development; household food waste

\section{Introduction}

Households are the major contributor to food waste [1]. A number of reasons can be linked to this problem, including attitudes towards food waste, poor handling of food, lack of time for proper planning, and overbuying cheap food [2-5]. However, most studies are focused on exploring the underlying drivers of the food waste problem, rather than on finding suitable solutions [5]. Against this backdrop, the purpose of the present research is to explore the relationship between packaging and food waste on the household level. Specifically, we ask: How do different packaging functions influence waste levels of different food products in households? This question has been identified as one of the most important to learn more about, in order to reduce food waste through packaging measures [6]. We focus on packaging systems, because improvements in this area is one approach to reduce food waste, as defined in the United Nations sustainability goal SDG 12.3 [7].

Yet, it is a complex task to design a packaging system that minimises the overall environmental impact of packed food products. There are many factors to consider: the environmental impact of the packaging system itself, the indirect environmental impact of how the packaging system contributes to efficient transportation, and special handling to avoid food waste. In order to minimise the total environmental impact, all of the investments in packaging materials should save more resources than they consume. For example, the environmental impact of manufacturing thicker material that adds protection must be less than the saved environmental impact of the reduced food waste. Hence, a packaging development team that aims to improve packaging in order to reduce food waste 
needs to know what packaging functions reduce food waste and to what extent. Two sets of knowledge are required for achieving this aim: first, product-specific knowledge is required, since reasons for food waste may differ between food categories; second, consumer-specific knowledge, including consumer needs, habits, and perceptions, as well as attitudes, norms, and economic conditions, are important fully understanding the interaction between packaging and food waste behavior. We aim to explore these two knowledge sets in a Swedish context, in line with the research question above.

The theoretical departure of this research is a service logic lens. The service logic shifts the focus from production processes and the unit of outputs as the key element of value creation (inside-out perspective) to the use process and how products and services support the end-user to create value (outside-in perspective) [8]. This means that the focus moves from the product itself to the process that it is used for and, as such, provides a better understanding of the interaction between packaging and the consumer [8,9]. From this perspective, packaging can be portrayed as a service; that is, a package has a number of functions that support consumers during their specific use contexts [10]. Thereby, the value of the package is uniquely determined by the consumer, depending on the context of use and can, for example, include the preserving of fresh food, supporting the handling and protection of food during purchase, the storage and use process, or providing information regarding ingredients, recipes, and food safety.

For a service to occur, a package must have functions that are aligned with user needs. To illustrate, if a package is easy to empty but the consumer never uses more than half of the contents and it throws the package into the waste bin unemptied, the service does not occur. Likewise, if a package is easy to reseal, but it provides unclear information regarding the food security of the opened package, the consumer might discard any leftovers after the first use. Thus, there is a delicate balance in the design of packaging functions that provide a service to different users and contexts, while at the same time reducing the food waste for different products.

A number of packaging functions that affect food waste levels can be found in the literature [11]. These include physical and chemical protection of the food content, package sizing, information on food security, and easy to empty functions, for example, [12-14]. In addition, there have been significant advances in technology to extend the shelf life of products [15-20]. However, the packaging functions that influence food waste are typically described in general terms without considering the underlying needs of consumers. For example, yoghurt may be wasted, because its containers are difficult to empty or because of uncertainty around date-labelling, thus, "easy to empty" and "information about food safety" are important features. In contrast, rice might not be wasted for the same reasons, but more likely as left-overs because consumers cook too much, hence, the functions "easy to measure" and "instructions" regarding how to measure portions for different needs may be more relevant. Therefore. a key aim of this article is to explore and integrate this consumer-specific knowledge and, in so doing, to inform the development of packaging solutions that are both useful and help to reduce food waste in households.

Both qualitative and quantitative measures are required to evaluate the impact of different packaging functions from the lens of service logic. For many packaging measures, such as smaller packaging size or reclosing functions, the relative environmental impact of the packaging versus the food content increases. There are a number of models that are available that calculate the trade-off between the environmental impact of packaging and food waste levels for different products, with respect to different end-of-life scenarios, for example, [13,21]. These models show that, for food products with a high environmental impact (for example, meat and dairy), it is often worth adding packaging material, even if the reduction in food waste is small. In contrast, for food products with a low environmental impact versus the packaging (for example, beverages), it is difficult to justify any investment in the packaging material at all to reduce food waste. To illustrate, Heller et al. calculated that the quota between the environmental impact of the food product versus its packaging was in the range 0.05 (for some beverages) to 1000 (for some meat) [22]. Although far from complete, these models can answer how much packaging material can be motivated to save a certain amount of food from being wasted. 
The second important question in regard to addressing the sustainability goal SDG 12.3 is how food waste can be reduced through the improvement of different packaging functions. This question focuses on whether investments in packaging material will ultimately reduce the total environmental impact during use. To answer this question, as highlighted above, requires not only product-specific knowledge, but also an in-depth understanding of consumer-specific knowledge to understand the service that a specific package provides to its user.

This research is divided into two studies to contribute to this understanding. Study 1 comprises a literature study to compile existing information regarding how packaging functions affect food waste. Study 2 builds on a knowledge gap that was identified in the literature study; that is, there are few insights on the relationship between packaging functions and food waste. Study 2 employs an expert workshop to generate deeper insights regarding packaging functions for selected products, as well as to explore obstacles and new possibilities for reducing food waste through packaging improvements, to address this knowledge gap. In combination, the studies contribute new insights for packaging design and policy making that aim to use packaging functions as a means to reduce the waste levels of different food products in households.

\section{Study I: Literature Review of Food Waste Data on Category/Product Level}

\subsection{Materials and Methods}

The databases SCOPUS and Web of Science have been used in the literature search to find peer reviewed articles regarding food waste in households. The search was restricted to articles that are written in English. The two main key words used are "Household food waste" (HFW) and "Household food loss" (HFL). The search was further modified by including "AND" and bread, dairy, drink, frozen food, fruit, meat, milk, and vegetables, respectively. If the title and abstract of the articles that were found in this search clearly indicated another focus area, for example, biogas production, composting, and food waste in other areas than households, they were excluded from further review. 51 articles were identified after this screening process.

These articles were examined and those that provided original quantitative food waste data in households on a category (dairy, meat, etc) and/or product (yoghurt, bacon, etc) level were selected for further analysis. Thereafter, a more detailed review was performed, as well as a search for other relevant articles from the references lists. Well-known "grey" literature, for example, reports from WRAP, was also added to the review. This led to a final pool of 23 articles, which were examined against the following questions:

1. What unit of analysis is used to quantify food waste? (\% of purchased, amounts, relative distribution of total waste, etc)

2. What research methods are used? (interviews, enquiries, diaries, or waste composition analysis (WCA))

3. Are there any reasons for food waste identified on a category/product level?

4. Are there any descriptions provided of how or when the food is wasted (in unopened packaging, from the refrigerator, left-overs, etc)?

5. Is there any information given regarding the packaging for wasted products?

The last three questions were used to identify the packaging functions that could influence the waste levels during the use process. If a reason for waste is stated in a paper, for example, that milk was wasted due to having passed the "best-before-date", there are several packaging functions that could logically be the root cause for waste. The amount of food in the packaging can be too great, so that the food is not consumed before the date is passed, and/or the information about food security is not clear enough, according to consumer knowledge. In some cases, the reason for waste was not stated, but there were some insights regarding how the food was wasted, or in what situation. This information could be used to identify the possible reasons for waste, before proceeding with the 
analysis, as described above. For example, the reason for food waste in an unopened packaging can be that the date is passed, or that the product contained ingredients that a member of the household is allergic to. The possible root causes of these reasons, regarding packaging functions, could be insufficient information about food safety, as mentioned above, or that the information about food ingredients is difficult to read. For leftovers, the packaging function "easy to dose" could be insufficient, but it may also be that a meat package contains $20 \%$ more than needed and that the surplus is cooked, because it is considered too little to save.

The links between how/when the food was wasted, reasons for food waste and packaging functions are defined and explained in Wikström et al. [23] (Section 2.2) and in Williams [12], and they are summarised in Table 1.

Table 1. The translation key for possible packaging functions that can be involved for different waste reasons, and descriptions of how or when the product is wasted.

\begin{tabular}{|c|c|c|}
\hline Reasons for Waste & How the Product Is Wasted & Possible Packaging Functions \\
\hline $\begin{array}{l}\text { Food wasted because its } \\
\text { bad }\end{array}$ & & $\begin{array}{l}\text { Information about how to store } \\
\text { Easy to reseal } \\
\text { Contains the right amount } \\
\text { Physical-chemical protection }\end{array}$ \\
\hline $\begin{array}{l}\text { Passed } \\
\text { "best-before-date" }\end{array}$ & & $\begin{array}{l}\text { Contains the right amount } \\
\text { Information about food safety }\end{array}$ \\
\hline Leakage & & Mechanical protection \\
\hline \multirow[t]{3}{*}{ Accidents; spillage } & & $\begin{array}{l}\text { Easy to grip } \\
\text { Easy to open } \\
\text { Easy to dose } \\
\text { Easy to reclose }\end{array}$ \\
\hline & Food wasted in original packaging & $\begin{array}{l}\text { Contains the right amount } \\
\text { Easy to empty } \\
\text { Information about food ingredients }\end{array}$ \\
\hline & Left-overs & $\begin{array}{l}\text { Contains the right amount } \\
\text { Easy to dose }\end{array}$ \\
\hline
\end{tabular}

The analysis in this paper identifies those packaging functions that can possibly be a reason for the food wasted, and thus feasible for improvement by better design in order to reduce the waste levels. However, how much of the wastage can be attributed to packaging functions is still uncertain on the product level, although there are strong indications for some products. As far as the authors know, the only estimate on how much food waste can be attributed to packaging functions is approximately $25 \%$ [12], but the figures are most probably higher for fresh products. Ten articles contained more information (see Table 2, questions 3-5) on quantitative food waste data and they were analysed in depth to identify the links between packaging functions and food waste. 
Table 2. Articles that included food waste data in households on a category and/or product level.

\begin{tabular}{|c|c|c|c|c|c|c|}
\hline & Method & $\begin{array}{l}\text { Category/Product } \\
\text { Waste Data }\end{array}$ & Unit for Food Waste & $\begin{array}{l}\text { Reasons for } \\
\text { Wastage * }\end{array}$ & $\begin{array}{l}\text { How Food Is } \\
\text { Wasted * }\end{array}$ & $\begin{array}{l}\text { Any Packaging } \\
\text { Information }\end{array}$ \\
\hline Bernstad et al [24] & WCA & Category & Relative distribution & & & $\checkmark$ \\
\hline Edjabou et al. [25] & WCA & Category & Mass; Relative distribution & & & \\
\hline Cronje et a.1 [26] & Survey & Product/Category & Relative distribution & & & \\
\hline Delley et al. [27] & Survey & Product/Category & Mass & & & \\
\hline Elimelech et al. [28] & WCA; Survey & Category & Mass; Relative distribution & & & \\
\hline Fehr et al. [29] & WCA & $\begin{array}{l}\text { Category(fruit and } \\
\text { vegetables) }\end{array}$ & Share of total waste & & & \\
\hline Hanssen et al. [30] & WCA; Survey & $\begin{array}{l}\text { Category, Survey on } \\
\text { product level. }\end{array}$ & $\begin{array}{c}\text { Mass; wasted product last } \\
\text { week }\end{array}$ & & & $\checkmark$ \\
\hline Janssen et al. [31] & Survey & $\begin{array}{c}\text { Product (fresh/ frozen } \\
\text { vegetables) }\end{array}$ & Fraction wasted & $\checkmark$ & $\boldsymbol{v}$ & $\boldsymbol{V}$ \\
\hline Jörissen et al. [32] & Survey & Product & $\begin{array}{l}\text { Items thrown away } \\
\text { often/sometimes }\end{array}$ & & & $\checkmark$ \\
\hline Lanfranchi et al. [33] & Survey & Products & $\begin{array}{l}\text { Relative distribution before } \\
\text { consumption }\end{array}$ & & & \\
\hline Langley et al. [34] & Diary & Category & Relative distribution & & & \\
\hline Lebersorger et al. [35] & WCA & Category & Relative distribution & & & \\
\hline Manios et al. [36] & Survey & $\begin{array}{l}\text { Product (fruits and } \\
\text { vegetables) }\end{array}$ & Mass & & & \\
\hline Quested et al. [37] & Diary; WCA & Product & $\begin{array}{l}\% \text { of purchased; several } \\
\text { others }\end{array}$ & $\boldsymbol{v}$ & $\checkmark$ & $\checkmark$ \\
\hline Silvennoinen et al. [38] & Diary & Category & Mass & $\checkmark$ & & \\
\hline Sonesson et al. [39] & Diary & Category/Product & Mass & & & \\
\hline Song et al. [40] & Survey & Product & Mass & & & \\
\hline
\end{tabular}


Table 2. Cont.

\begin{tabular}{|c|c|c|c|c|c|c|}
\hline & Method & $\begin{array}{l}\text { Category/Product } \\
\text { Waste Data }\end{array}$ & Unit for Food Waste & $\begin{array}{l}\text { Reasons for } \\
\text { Wastage * }\end{array}$ & $\begin{array}{l}\text { How Food Is } \\
\text { Wasted * }\end{array}$ & $\begin{array}{l}\text { Any Packaging } \\
\text { Information }\end{array}$ \\
\hline Stensgård et al. [41] & WCA; Survey & $\begin{array}{l}\text { Category (WCA); } \\
\text { Product (survey) }\end{array}$ & Mass; waste frequency & $\checkmark$ & $\checkmark$ & \\
\hline Stensgård et al. [42] & Survey & Product & Waste frequency & $\checkmark$ & $\checkmark$ & \\
\hline Syversen et al. [43] & WCA & Category & $\begin{array}{c}\text { Mass; relative distribution } \\
\text { of categories }\end{array}$ & & & \\
\hline Szabo et al. [44] & Survey & Category & Mass & & & \\
\hline Williams et al. [12] & Diary & Category & Mass & $\checkmark$ & & $\checkmark$ \\
\hline Østergaard et al. [45] & Survey & Product (bread) & Slices of bread wasted & $\checkmark$ & & $\boldsymbol{V}$ \\
\hline
\end{tabular}

NOTES: A checkmark indicates that the respective article has investigated the reasons for waste (column 5), how food is wasted (column 6), or provided information about the packaging (column 7). WCA: Waste Composition Analysis, Relative distribution: distribution of waste between products/categories. *on a product/category basis (how = in unopened packaging, prepared, etc) 


\subsection{Results of the Literature Review}

The reasons for waste on either a category or product level were explicitly stated in seven studies only, as can be seen in Table 2, but descriptions regarding how and when the food is wasted can also indicate the reason for waste, as mentioned above. Descriptions of the packaging format for the wasted products were almost absent across the identified studies. Thus, the available information limits analysis. However, the information in the studied articles does clearly indicate some packaging measures with the potential to decrease the waste levels. All of the waste figures exclude unavoidable food waste, such as bones and tea bags.

Few articles evaluated reasons for wastage and very few provided any information regarding packaging. Below, the findings from the literature are discussed in more depth by distinguishing between food waste across various food product categories.

\subsubsection{Bread}

A large share of purchased bread is wasted in households. In a United Kingdom (UK) study, $29 \%$ of purchased bread was estimated to be wasted [37], and several studies confirm that bread is wasted to a high degree [30]. In the UK study, most bread was wasted before being used in the preparation of sandwiches, and about $1 / 3$ of the wasted bread was disposed of in its original packaging. Few $(10-15 \%)$ mention the date label as the reason for waste [37,42]. The main reason why bread is wasted seems to be that it is degraded in freshness, presumably that it dries out [38] or loses its crispiness [30]. In a Norwegian study, Østergaard found that the "low-wasters" of bread repacked and used the freezer as a strategy to avoid waste [45]. Low-wasters also frequently used the toaster to improve the quality of dry bread.

The literature clearly indicates that the amount of bread per package is too high to be used in the appropriate time in many households. Smaller loaves and/or fewer slices per package seems to be a straightforward strategy. Freezing might be a strategy to reduce waste, but so long as the electricity is based on fossil fuels, freezing and toasting would have to save more than $50 \%$ of bread from being wasted to reduce the climate impact (personal calculations), thus smaller loaf size is a preferable strategy in most cases.

\subsubsection{Cheese}

$9 \%$ of purchased cheese was estimated to end up as waste in the UK study, which was mostly classified as avoidable. The reason for $77 \%$ of this waste was "not used in time" and about $1 / 3$ of that was due to passed date. $42 \%$ of the waste was thrown in its original packaging, where most of the packaging was opened [37]. No other studies provided information about how the cheese was wasted or why.

When properly stored, cheese can be maintained at a high quality for a long time. As a large share is wasted or unused, without citing date labelling as a reason, a probable reason is insufficient protection during storing. Cheese is seldom sold in packaging with a reclosing function. As the environmental impact of cheese is very high when compared to its packaging [46], it can be justifiable to invest in more packaging material, adding reclosing functions and/or lower amounts of cheese per package.

\subsubsection{Milk}

In the UK study, the reasons for approximately half of the avoidable milk waste were not related to packaging, for example, "served to much". The reason for the other half was that it was not used in time [37]. Of this, the majority was wasted without citing date as the reason, which is in contrast to a Finnish study, where the most common reason was that the date was passed [38]. Accidents, which may be related to packaging functions, was cited as a reason for only $4 \%$ of the waste [37].

Lower amounts of milk per package and better information regarding date labelling seem to be the best packaging strategies to avoid waste. Different information strategies in Norway, for example, 
a new date label "best before-but not bad after" have significantly reduced date labels being a reason for waste [42].

\subsubsection{Yoghurt}

About $9 \%$ of purchased yoghurt ended up as waste in the UK study [37]. The reason for 70\% of this waste was because the date label was passed. This is of similar magnitude as in Norway during the years 2010-2015, but information activities in Norway, as mentioned above, reduced the numbers citing data as a reason for the waste of yoghurt to $16 \%$ during 2018 [42].

Notably, the large fraction of unopened yoghurt packaging (about $50 \%$ of avoidable waste) in the UK study indicates that the number of pots should be reduced in multipacks. A standard yoghurt pack in the UK is typically $4 \times 125 \mathrm{~g}$ [37].

For yoghurt, improved information regarding the meaning of date labelling seems to be the most appropriate packaging measure, also in addition to avoiding multipacks.

\subsubsection{Meat and Fish}

The share of avoidable waste for beef, pork, and poultry in the UK study were 8,12 , and $13 \%$, respectively. Cooked or prepared too much, together with not-used-in-time, were the most common causes. Notable is the high amount of pork that was wasted in its original packaging, which in many cases was more than half full. Accidents was the reason for $19 \%$ of the avoidable beef waste, although it was unknown if the accidents happened during preparation or during cooking. The date label was the reason for $20-31 \%$ of avoidable waste [37].

Stensgaard [41] found that the date label was the reason for $58 \%$ of the wastage occasions of charcuterie, but this figure dropped to $15 \%$ during 2018 [42]. For fish/fish products, the passed the date reason dropped from $33 \%$ to $17 \%$ during the same period, due to the information activities that are mentioned above. Packages being too large was noted by the respondents much more frequently for fish than other products.

A smaller amount of meat/fish per package seems to be an appropriate measure to reducing wastage. The high share of "cooked/prepared to much" responses may also indicate amounts being too large; if the amount of meat/fish is $20-30 \%$ more than needed, the decision might be to prepare/cook the surplus instead of saving it in the refrigerator. Adding more packaging material to reduce waste is highly justified for meat products because of the high environmental impact of meat production. It would appear that more informative date labelling, together with information activities, is needed.

\subsubsection{Fruits and Vegetables}

The main reason for the wastage of fruits and vegetables is that they have degraded in quality [37,42]. These products are sold both loose and packed. It is difficult to speculate about the role of packaging in household wastage, as there was no information about the share of packed fruits or vegetables. Packaging can sometimes increase the shelf life of these products by several days and help to reduce wastage [47]. However, fixed amounts of the product, for example, oranges in a net bag, grapes, or tomatoes in plastic packaging, may make the consumer buy more than they need and later waste for that reason. The relatively low environmental impact of fruits and vegetables requires calculations to ensure that more packaging material to reduce product loss and waste is environmentally motivated.

\subsubsection{Other Products}

Generally, staples seem to constitute a small part $(<10 \%)$ of avoidable waste according to data from the selected articles. For many products, such as rice and pasta, most of the avoidable wastage is left-overs from the table. In these cases, better dose instructions may help to decrease wastage. In the UK study, "not used in time" was the reason for about half of the avoidable waste of confectionary and snacks, condiments, sauces, herbs and spices, and cakes and desserts [37], which indicates that smaller package sizes may be an option to reduce the wastage of these products. 
A Dutch study compared the waste levels for a number of products, depending on whether they were sold fresh, frozen, or ambient (canned or in glass jars) [31]. Especially for spinach, broccoli, battered fish, potato products, and berries, the wastage of frozen products was significantly lower than for fresh products. One explanation for this could be that the consumer can choose the amount that is needed on each meal occasion from these kinds of frozen products. In the same study, the respondents reported a high wastage of food from ambient products directly after consumption. A possible explanation is that the amounts of food in canned products are more than needed, and saving the surplus is not experienced as a suitable option. A notable observation in this study is also that $38 \%$ of the wastage of food from the freezer was due to the expiry date.

\subsubsection{General Observations}

The literature supports that there are two major routes for the wastage of food: (1) that a packaging is partly emptied and that the remainder is put in the refrigerator until the content has deteriorated or the date has expired and (2) left-overs. Although not being investigated in these studies, pack size may also contribute to the wastage of left-overs. If the amount of food is slightly more than is needed, then consumers may choose to prepare more instead of saving small amounts. Several studies report higher waste per capita for one to two person households [12,30,32] and to some extent in [25], and the pack size can be one reason for that. From a packaging point of view, it is clear that the two most important packaging functions to improve the reduction of food waste are "contains the right amount" and "information about food safety". Smaller pack size is suggested in several studies [12,32,34,37].

However, the right amount may be very different for different products and households. For products that are used on an irregular basis and/or have a short shelf-life, the amount may be adapted to be fully used for one meal. Unfortunately, that amount differs between different households. For products with a high environmental impact relative to its packaging, it can be environmentally motivated to adapt the amount to single households, which means that larger households use two to three packs if different packaging sizes is not an option. On the other hand, smaller pack sizes may not be environmentally motivated for food that is used regularly, has a long shelf-life in opened packaging or it has a low environmental impact when compared to its packaging.

The reduction of food wasted due to date in the UK [37] and Norway [42] clearly shows that information activities and better date labelling have high potential and are relatively simple measures to achieve waste reductions.

There is no food waste reported due to broken packaging or leakage in the selected articles. The mechanical protection of food products seems to be of sufficient quality in the countries studied, at least on the household level. The amount of food waste due to incorrect storage is only evaluated in the Norwegian studies [41,42], where consumers stated the incorrect storing during transport or in the home as a reason for waste. There are a few notations regarding the incorrect storage of vegetables being a possible reason for waste $[37,38]$ and several comments about using the freezer to avoid food waste. However, presumably a significant amount of food waste can be reduced by better storage conditions.

Improvements of the function "information about how to store", for example, by a label with the optimal storing temperature or how long the product can be stored in the freezer will most likely reduce food waste for vegetables and some other products. The packaging function "easy to reclose" can also have an effect on durability, and thus waste levels, but the importance of this function has not been investigated in household food waste studies.

For most products, only a small percentage of reported food waste is attributed to accidents [12,37]. There are also other reasons than packaging for the accidents, for example, children dropping food on the floor. Thus, improvements of the functions "easy to open" and "easy to handle" seem to have almost no potential to reduce food waste in most cases. In contrast, a study by Duizer et al. [48] showed that the elderly often spilled food during opening and handling. However, this spillage, may be small 
when compared to the total amount wasted. It may also be that the elderly are underrepresented in the studies.

The share of avoidable waste that was thrown away in its original packaging was 19\% [37], $28 \%$ [30], and $42 \%$ [24]. Furthermore, only $11 \%$ of this waste was found in packaging with less than $25 \%$ of the content remaining [37]. This means that the function "easy to empty" is of minor importance for the majority of food that is wasted. In contrast, this function was the second most cited reason for wastage due to packaging in the study by Williams et al. [12]. This difference can probably be explained by differences in attitudes and behaviour among the participants, as the wasted amounts were very low in the study by Williams.

\section{Study II: Expert Workshop}

Study 2 builds on the literature study to generate deeper insights on how packaging functions can help to reduce food waste, as well as to explore obstacles and possibilities that are related to new packaging solutions.

\subsection{Materials and Methods}

The authors of this paper conducted a workshop at the conference Packbridge Day, Lund, Sweden on the 26th of April 2018. This conference is a forum for packaging researchers, practitioners (for example, marketing, R\&D, process and management), and NGOs. After some information about the procedure and some complementary information regarding packaging formats for the products, the participants were asked to fill in an individual questionnaire. The participants judged the potential for improvements in different functions to reduce food waste for bread in a plastic bag, mixed salad in a plastic bag $(65 \mathrm{~g})$, milk in a gable top tetra (1 1), yoghurt in containers (multipack $4 \times 125 \mathrm{~g}$ ), sliced ham in plastic packaging (400 g), yoghurt in a gable top tetra (1 1), and finally sausage (12 pcs, $960 \mathrm{~g})$ in plastic packaging. As an illustrative example, Figure 1 shows the questionnaire for bread. There were also pictures provided for every product. These products were selected because of a relatively high environmental impact and/or that the products are wasted to a relative high extent.

\begin{tabular}{|l|l|c|c|c|c|c|}
\hline & BREAD in plastic bag & & & & & \\
\hline Impact on food waste levels & $\begin{array}{c}\mathbf{1} \\
\text { No } \\
\text { effect }\end{array}$ & $\begin{array}{c}\mathbf{2} \\
\text { Small } \\
\text { effect }\end{array}$ & $\begin{array}{c}\mathbf{3} \\
\text { Moder } \\
\text { ate } \\
\text { effect }\end{array}$ & $\begin{array}{c}\mathbf{4} \\
\text { High } \\
\text { effect }\end{array}$ & $\begin{array}{c}\mathbf{5} \\
\text { Very } \\
\text { high } \\
\text { effect }\end{array}$ \\
\hline 1 & Easier to empty & & & & & \\
\hline 2 & Easier to open & & & & & \\
\hline 3 & Less amount of food & & & & & \\
\hline 4 & Easier to reclose & & & & & \\
\hline 5 & Better information of ingredients & & & & & \\
\hline 6 & $\begin{array}{l}\text { Better information about when the } \\
\text { food can be consumed safely }\end{array}$ & & & & & \\
\hline 7 & Easier to handle & & & & & \\
\hline 8 & $\begin{array}{l}\text { Better protection of food quality - in } \\
\text { unopened packaging }\end{array}$ & & & & & \\
\hline 9 & $\begin{array}{l}\text { Better protection of food quality- in } \\
\text { opened packaging }\end{array}$ & & & & & \\
\hline 10 & Easier to dose correct quantity & & & & & \\
\hline
\end{tabular}

Figure 1. The individual questionnaire for bread. The impact on food waste for different improvements of packaging functions are rated on a Likert scale (1-5).

A total of 42 participants attended the workshop, with about half of them being from private businesses, (mostly marketing, R\&D, and management), while the other half mostly represented universities and NGO's. All family sizes were represented, from one to five members; 
however, single households were underrepresented, with a share of only $12 \%$. The gender distribution was about equal ( $42 \%$ men) and $70 \%$ had more than ten years of experience in their profession.

After the individual sessions, the participants were assigned to groups in which they were asked to select and discuss products that they believed had a good potential to reduce food waste through improved packaging functions. Within a 30-minute timeframe, they were also asked to discuss obstacles for packaging improvements and some possibilities to overcome these obstacles.

Notes: For the products below, judge how the different actions will reduce food waste in households. $1=$ no effect on waste levels, $3=$ moderate effect, $5=$ high effect

\subsection{Results of the Expert Workshop}

\subsubsection{Individual Questionnaire and Group Discussions about Specific Products}

Figure 2 shoed the scores from the experts on how the different packaging actions might reduce food waste in households. Some functions scored high for most products; "smaller amount of food", "easier to reclose" (for products without that function), "better information about when the food can be consumed safely", and "better protection of food quality-in opened packaging". However, there are certainly different priorities between functions on the different products. "Better protection of food quality-in opened packaging" scored high for bread (2.1), lettuce (2.2), sliced ham (2.5), and sausage (2.7), indicating that these products are wasted due to quality deterioration before all of the food is consumed. This function correlates to "smaller amount of food" and in the group discussions there were suggestions to select either less food or better protection as a strategy. For example, it is difficult to protect mixed lettuce once the packaging is opened, because the protecting gas is lost, as comments from participants also highlight: "I waste it a lot of the time. It goes slimy. It smells". In that case, a smaller amount of salad is the most realistic option.

"Easier to empty" scores high for yoghurt only $(2.4,2.6)$, naturally because of the high viscosity of the product. There were many comments in the group discussions regarding the difficulty of emptying the yoghurt pots "sharp corners making them difficult to empty" and the gable top "always left"; "difficult to check how much is left". Notable is the score for "easier to reclose" for the yoghurt multipack, which indicates that the $125 \mathrm{~g}$ content is more than what is consumed in some cases. On the other hand, one group suggested an increase of the content to $175 \mathrm{~g}$ to be better adapted to a single serve. This underlines the different needs, and that single-serve packaging should be offered in different sizes.

Some more product-specific information functions came up in the group discussions: about correct storage temperatures (bread, lettuce), how to smell and taste quality (yoghurt), that bread can be put in the freezer, and how long you can store opened packaging safely or with good quality (bread, ham and yoghurt). The dynamic best-before dates were also suggested.

Several experts shared that ham packaging often spent a long time on the breakfast table. One participant described: "this is a breakfast product for me, that is, it stays out in room temperature for a long time (kids have breakfast at different times". In addition, there were many remarks about the size of the sausage and ham packaging being to big: "too many sausages for a small family", "always two sausages left", and "it (ham) goes slimy, so rather play safe than sorry". A large amount of ham slices in a pack without a reclosing function certainly increases the risk that the last slices will deteriorate. There were also some remarks that more knowledge regarding how products are used in households is needed.

Other comments from the group discussion pointed out that the milk packages are often too heavy for children: "my kids often pour more milk than they actually need, maybe since the package is heavy", or too big: "we only drink milk in coffee; low usage daily". Some noted that the habit of some consumers to repack the food in their own packaging means that information and the protective properties of the original packaging are lost. 

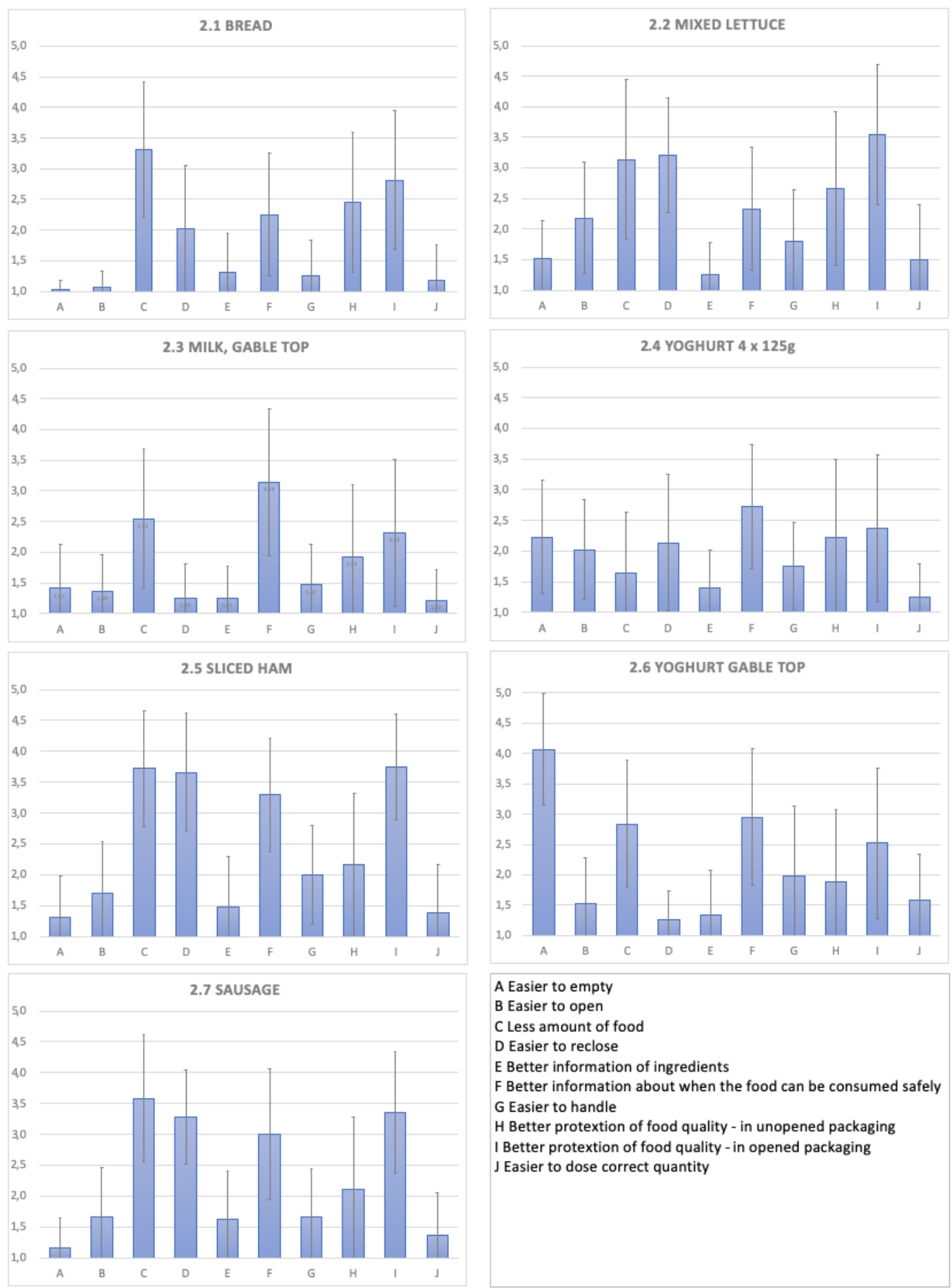

Figure 2. The experts ranked how the different packaging actions (A-J) might reduce food waste in households for seven fresh products. The Likert scale is from 1 (no effect) to 5 (very high effect). Standard deviation indicated.

The comments above indicate that the experts mostly discussed issues from their own private experiences of how food and packaging are handled in households. This confirms the need for more professional knowledge regarding how packaging functions influence food waste at the product level. Furthermore, from the average score of the functions, it seems that the experts ranking confirms the findings from the literature review. However, here it needs to be noted that the variation in scores between the experts is quite significant (see standard deviation in Figure 2). On the one hand, 
the variation may be attributed to different perceptions of the scale. A "Very high" impact on food waste levels may be interpreted in different ways, as there are many other factors that influence food waste levels. On the other hand, it confirms that the relationship between packaging and food waste is highly contextual and dependent on the consumer's specific needs (for example, single household vs. large families).

\subsubsection{Obstacles and Opportunities}

The participants also identified several obstacles for packaging improvements in order to reduce the food waste. The most common obstacles were linked to the lack of economic incentives for companies to act. Smaller packaging sizes means higher costs per unit of food and the participants did not think that consumers would be prepared to meet that cost. The lack of demand from consumers hampers investment in new packaging machinery to improve packaging functions. In addition, participants questioned whether consumers would actually change their behavior. One participant highlights the dilemma of higher costs for improved packaging: "who will take the cost is a much bigger question than I originally thought".

It was also pointed out that there must be global agreements and cooperation on the relationship between packaging and food waste. Several groups suggested the need for strong policy statements about food waste and packaging, and cross-national measures and economic taxes to highlight the importance of packaging in saving food. Information and the education of consumers were also mentioned, as well as more cooperation across the whole value chain. The lack of knowledge about how packaging functions influence food waste at the product level was also highlighted.

\section{Conclusions}

This study confirms that the question of how packaging functions influence food waste on a product level remains largely unexplored. This is despite the fact that there seems to be a high potential to reduce food waste by better aligning packaging functions to users' specific needs and habits. Both the literature study and the expert workshop indicate that less food per packaging and better information about food safety and storage may help to reduce food waste, but also that product-specific considerations are necessary. For example, with knowledge of the use of sliced ham for breakfast, a packaging development team could consider the appropriate size, reclosing, and other protection functions to ensure that the ham is consumed before it turns bad. We conclude that household studies that explicitly focus on the relationship between packaging functions and food waste on a product level are needed for further exploring this relationship.

There have been considerable advances in technology to improve the shelf-life of products during the last years, as mentioned in the introduction. Shelf life is represented here by the function "protection of food quality-in unopened packaging". The improvements of shelf-life have economic incentives for companies, because it helps to decrease waste before sale. Yet, our findings indicate that more attention should be directed to the function "protection of food quality-in opened packaging". A large share of the food waste emanates from food that has been partly but not completely used before the "best before date" is passed or the quality has deteriorated. This waste can be addressed in several ways, such as by reducing the amount of food, by adding protective functions of the packaging for after opening, information regarding how to store properly and adding information about how to judge the food safety of the product. The recent drop in food waste in Norway and the UK suggest that such initiatives can be effective in addressing goal SDG 12.3. However, additional studies are required to investigate how products are used in different households and in different markets.

Besides the lack of knowledge about which packaging functions are the most important to improve for different products, the experts identified several obstacles to realise such improvements. Less amount of food per package, and added protective functions will increase the costs per $\mathrm{kg}$ of food sold. Consumers might not be motivated to meet that cost at the selling point, although they may save money from reduced food waste at home. The lack of demand from consumers might 
also hamper investments in new packaging material or equipment. An additional obstacle is the environmental opinion on packaging material itself. From a scientific point of view, it is clear that investments in packaging material to reduce the food waste of products with high environmental impact are environmentally motivated. Another factor that can motivate greater use of packaging materials to reduce food waste is the fact that a high amount of food is wasted in its original packaging, thus it is not feasible to recycle the food residues, nor the packaging material. To our knowledge, this is not considered in environmental evaluations of packaging. Policy making and educational efforts are required to inform consumers about the purpose of packing and to incentivise producers and distributors to actively help in reducing the amount of food that is wasted on the household level.

We conclude with the call to more clearly disseminate the environmental benefits of packaging to reduce food waste. In this way, authorities, researchers, companies, and NGOs can take a first step in helping environmentally concerned consumers to make more balanced decisions. However, there must also be an awareness that this is not true for all products, and it also depends on the end-of-life for food waste and packaging. The food-to-packaging ratio calculations by Heller et al. [22] serve as a good reminder to also consider product-specific data.

Author Contributions: F.W. planned and conducted the major part of the literature research, based on the project application mentioned below (Formas). Z.R. conducted the literature search and the initial selections. F.W., H.W. and J.T. jointly designed the expert workshop; F.W. and H.W. conducted it. F.W. conducted the major part of the analysis of the expert workshop, with contributions from H.W. and J.T., F.W. drafted the manuscript. All authors contributed references, comments and revisions and approved the final manuscript.

Funding: This research was funded by the research grant FR2016/0005 (Formas, Sweden) and Vinnväxt TPP 2.0 (\#2016-04227).

Acknowledgments: The authors are grateful to the organisation Packbridge that made it possible to conduct the expert workshop, and to the experts that participated.

Conflicts of Interest: The authors declare no conflict of interest.

\section{References}

1. Stenmarck, Å.; Jensen, C.; Quested, T.; Moates, G. Estimates of European Food Waste Levels; IVL Swedish Environmental Research Institute: Stockholm, Sweden.

2. Aschemann-Witzel, J.; de Hooge, I.; Amani, P.; Bech-Larsen, T.; Oostindjer, M. Consumer-Related Food Waste: Causes and Potential for Action. Sustainability 2015, 7, 6457-6477. [CrossRef]

3. Thyberg, K.L.; Tonjes, D.J. Drivers of food waste and their implications for sustainable policy development. Resour. Conserv. Recycl. 2016, 106, 110-123. [CrossRef]

4. Stancu, V.; Haugaard, P.; Lahteenmaki, L. Determinants of consumer food waste behaviour: Two routes to food waste. Appetite 2016, 96, 7-17. [CrossRef]

5. Hebrok, M.; Boks, C. Household food waste: Drivers and potential intervention points for design-An extensive review. J. Clean. Prod. 2017, 151, 380-392. [CrossRef]

6. Wikström, F.; Verghese, K.; Auras, R.; Olsson, A.; Williams, H.; Wever, R.; Grönman, K.; Kvalvåg Pettersen, M.; Møller, H.; Soukka, R. Packaging Strategies That Save Food: A Research Agenda for 2030. J. Ind. Ecol. 2018. [CrossRef]

7. Resolution Adopted by the General Assembly on 25 September 2015. Transforming Our World: The 2030 Agenda for Sustainable Development; UN: New York, NY, USA, 2015.

8. Edvardsson, B.; Gustafsson, A.; Roos, I. Service portraits in service research: A critical review. Int. J. Serv. Ind. Manag. 2005, 16, 107-121. [CrossRef]

9. Vargo, S.L.; Lusch, R.F. Evolving to a New Dominant Logic for Marketing. J. Mark. 2004, 68, 1-17. [CrossRef]

10. Jelsma, J. Designing 'moralized' products theory and practice. In User Behavior and Technology Development; Verbeek, P.P., Slob, A., Eds.; Springer: Dordrecht, The Netherland, 2006; pp. 221-231.

11. Lindh, H.; Williams, H.; Olsson, A.; Wikström, F. Elucidating the Indirect Contributions of Packaging to Sustainable Development: A Terminology of Packaging Functions and Features. Packag. Technol. Sci. 2016, 29, 225-246. [CrossRef] 
12. Williams, H.; Wikström, F.; Otterbring, T.; Löfgren, M.; Gustafsson, A. Reasons for household food waste with special attention to packaging. J. Clean. Prod. 2012, 24, 141-148. [CrossRef]

13. Silvenius, F.; Grönman, K.; Katajajuuri, J.-M.; Soukka, R.; Koivupuro, H.-K.; Virtanen, Y. The Role of Household Food Waste in Comparing Environmental Impacts of Packaging Alternatives. Packag. Technol. Sci. 2013, 27, 277-292. [CrossRef]

14. Verghese, K.; Lewis, H.; Lockrey, S.; Williams, H. Packaging's Role in Minimizing Food Loss and Waste Across the Supply Chain. Packag. Technol. Sci. 2015, 28, 603-620. [CrossRef]

15. Murray, S. Moveable Feasts: From Ancient Rome to the 21st Century, the Incredible Journeys of the Food We Eat; St Martins: New York, NY, USA, 2008.

16. Steel, C. Hungry City. How Food Shapes Our Lives; Vintage: London, UK, 2013.

17. Twede, D. The packaging technology and science of ancient transport amphoras. Packag. Technol. Sci. 2002, 15, 181-195. [CrossRef]

18. Gutierrez, M.M.; Meleddu, M.; Piga, A. Food losses, shelf life extension and environmental impact of a packaged cheesecake: A life cycle assessment. Food Res. Int. 2017, 91, 124-132. [CrossRef]

19. Yildirim, S.; Röcker, B.; Pettersen, M.K.; Nilsen-Nygaard, J.; Ayhan, Z.; Rutkaite, R.; Radusin, T.; Suminska, P.; Marcos, B.; Coma, V. Active Packaging Applications for Food. Compr. Rev. Food Sci. Food Saf. 2018, 17, 165-199. [CrossRef]

20. Cacciotti, I.; Mori, S.; Cherubini, V.; Nanni, F. Eco-sustainable systems based on poly(lactic acid), diatomite and coffee grounds extract for food packaging. Int. J. Biol. Macromol. 2018, 112, 567-575. [CrossRef]

21. Wikström, F.; Williams, H. Potential environmental gains from reducing food losses through development of new packaging-A life-cycle model. Packag. Technol. Sci. 2010, 23, 403-411. [CrossRef]

22. Heller, M.C.; Selke, S.E.M.; Keoleian, G.A. Mapping the Influence of Food Waste in Food Packaging Environmental Performance Assessments. J. Ind. Ecol. 2018. [CrossRef]

23. Wikström, F.; Williams, H.; Verghese, K.; Clune, S. The influence of packaging attributes on consumer behaviour in food-packaging life cycle assessment studies-A neglected topic. J. Clean. Prod. 2014, 73, 100-108. [CrossRef]

24. Bernstad Saraiva Schott, A.; Andersson, T. Food waste minimization from a life-cycle perspective. J. Environ. Manag. 2015, 147, 219-226. [CrossRef]

25. Edjabou, M.E.; Petersen, C.; Scheutz, C.; Astrup, T.F. Food waste from Danish households: Generation and composition. Waste Manag. 2016, 52, 256-268. [CrossRef]

26. Cronjé, N.; Merwe, I.v.d.; Müller, I.-M. Household food waste: A case study in Kimberley, South Africa. J. Consum. Sci. 2018, 46, 1-9. [CrossRef]

27. Delley, M.; Brunner, T.A. Foodwaste within Swiss households: A segmentation of the population and suggestions for preventive measures. Resour. Conserv. Recycl. 2017, 122, 172-184. [CrossRef]

28. Elimelech, E.; Ayalon, O.; Ert, E. What gets measured gets managed: A new method of measuring household food waste. Waste Manag. 2018, 76, 68-81. [CrossRef] [PubMed]

29. Fehr, M.; Romao, D.C. Measurement of fruit and vegetable losses in Brazil-A case study. Environ. Dev. Sustain. 2001, 3, 253-263. [CrossRef]

30. Hanssen, O.J.; Syversen, F.; Stø, E. Edible food waste from Norwegian households—Detailed food waste composition analysis among households in two different regions in Norway. Resour. Conserv. Recycl. 2016, 109, 146-154. [CrossRef]

31. Janssen, A.M.; Nijenhuis-de Vries, M.A.; Boer, E.P.J.; Kremer, S. Fresh, frozen, or ambient food equivalents and their impact on food waste generation in Dutch households. Waste Manag. 2017, 67, 298-307. [CrossRef] [PubMed]

32. Jörissen, J.; Priefer, C.; Bräutigam, K.-R. Food Waste Generation at Household Level: Results of a Survey among Employees of Two European Research Centers in Italy and Germany. Sustainability 2015, 7, 2695-2715. [CrossRef]

33. Lanfranchi, M.; Calabrò, G.; De Pascale, A.; Fazio, A.; Giannetto, C. Household food waste and eating behavior: Empirical survey. Br. Food J. 2016, 118, 3059-3072. [CrossRef]

34. Langley, J.; Yoxall, A.; Heppell, G.; Rodriguez, E.M.; Bradbury, S.; Lewis, R.; Luxmoore, J.; Hodzic, A.; Rowson, J. Food for thought? - A UK pilot study testing a methodology for compositional domestic food waste analysis. Waste Manag. Res. 2010, 28, 220-227. [CrossRef]

35. Lebersorger, S.; Schneider, F. Discussion on the methodology for determining food waste in household waste composition studies. Waste Manag. 2011, 31, 1924-1933. [CrossRef] 
36. Manios, Y.; Harizani, K.; Markakis, G.; Galani, P.; Manios, T. Relating fruit and vegetable consumption in households with residue generation and utilization in the city of Heraklion, Crete, Greece. Int. J. Sustain. Dev. World Ecol. 2009, 12, 353-360. [CrossRef]

37. Quested, T.; Murphy, L. Household Food and Drink Waste: A Product Focus; WRAP: Oxon, UK, 2014.

38. Silvennoinen, K.; Katajajuuri, J.-M.; Hartikainen, H.; Heikkilä, L.; Reinikainen, A. Food waste volume and composition in Finnish households. Br. Food J. 2014, 116, 1058-1068. [CrossRef]

39. Sonesson, U.; Anteson, F.; Davis, J.; Sjödén, P.-O. Home Transport and Wastage: Environmentally Relevant Household Activities in the Life Cycle of Food. Ambio J. Hum. Environ. 2005, 34, 371-375. [CrossRef]

40. Song, G.; Li, M.; Semakula, H.M.; Zhang, S. Food consumption and waste and the embedded carbon, water and ecological footprints of households in China. Sci Total Environ. 2015, 529, 191-197. [CrossRef]

41. Stensgård, A.E.; Hanssen, O.J. Matsvinn i Norge 2010-2015. Sluttrapport fra ForMat-Prosjektet; Østfoldforskning: Kråkerøy, Norway, 2016; Available online: https://www.matvett.no/uploads/documents/ForMat-rapport2016.-Sluttrapport.pdf (accessed on 4 May 2018).

42. Stensgård, A.E.; Prestrud, K.; Hanssen, O.J.; Callewaert, P. Matsvinn i Norge. Rapportering av Nøkkeltall 2015-2017; Østfoldforskning: Kråkerøy, Norway, 2018; Available online: https://www.matvett.no/uploads/ documents/OR.28.18-Edible-food-waste-in-Norway-Report-on-key-figures-2015-2017.pdf (accessed on 10 December 2018).

43. Syversen, F.; Hanssen, O.J.; Bratland, H.; Stensgård, A.; Bjørnerud, S. Nasjonal beregning av mengde matsvinn på forbrokarleddet. Avfall Norge, Oslo. 2018. Available online: https://www.miljodirektoratet.no/ globalassets/publikasjoner/M1016/M1016.pdf (accessed on 10 December 2018).

44. Szabó-Bódi, B.; Kasza, G.; Szakos, D. Assessment of household food waste in Hungary. Br. Food J. 2018, 120, $625-638$. [CrossRef]

45. Østergaard, S.; Hanssen, O.J. Wasting of Fresh-Packed Bread by Consumers-Influence of Shopping Behavior, Storing, Handling, and Consumer Preferences. Sustainability 2018, 10, 2251. [CrossRef]

46. Williams, H.; Wikström, F. Environmental impact of packaging and food losses in a life cycle perspective: A comparative analysis of five food items. J. Clean. Prod. 2011, 19, 43-48. [CrossRef]

47. Dhall, R.K.; Sharma, S.R.; Mahajan, B.V. Effect of shrink wrap packaging for maintaining quality of cucumber during storage. J. Food Sci. Technol. 2012, 49, 495-499. [CrossRef] [PubMed]

48. Duizer, L.M.; Robertson, T.; Han, J. Requirements for packaging from an ageing consumer's perspective. Packag. Technol. Sci. 2009, 22, 187-197. [CrossRef] 